\title{
Estimation of Global Solar Radiation and Optimal Tilt Angles of Solar Panels for Pune, India
}

\author{
Pramod Manjunath $^{1}$, D. Devaprakasam ${ }^{2,3}$, Dipen Paul ${ }^{1 *}$ \\ ${ }^{1}$ Department of Energy and Environment, Symbiosis Institute of International Business, Symbiosis International (Deemed \\ University), Pune 411057, Maharashtra, India \\ ${ }^{2}$ Department of Mechanical Engineering, Applied Research Lab, School of Mechanical Engineering, Vellore Institute of \\ Technology, Chennai 600127, Tamil Nadu, India \\ ${ }^{3}$ InCUBE-EngSciRes R\&D, Alpha Academy Tech®, Udumalpet, Coimbatore, Tamil Nadu 642126, India
}

Corresponding Author Email: dipen.paul@siib.ac.in

https://doi.org/10.18280/ijdne.160111

Received: 1 January 2021

Accepted: 18 February 2021

\section{Keywords:}

efficiency, optimal tilt, solar radiation

\begin{abstract}
Solar panels can achieve the highest yield when they are oriented in the right way as the influence of the tilt angles can lead to a high impact on the performance. This paper demonstrates the effect of the tilt angle on the final yield and maximum utilization of solar energy. The annual optimal tilt angle of the solar panels for Pune was found out using the Liu and Jordan model. The optimal tilts yielding an increase of $7 \%$ was found out to be $0^{\circ}$ on the months starting from April and lasting till September and $40^{\circ}$ starting from October and holding at $40^{\circ}$ till March. By changing the tilt angle every month, there was an increase in the yield by more than $8 \%$. For better yield and maximum utilization of solar energy, optimizing the tilt angles of solar panels monthly or even twice a year is effective based on the study. Most of the panels are fixed at an angle equal to the latitude of the place and oriented towards the Southern sky in the northern hemisphere. Measurements of the monthly average global solar radiation, monthly average temperatures, and monthly average relative humidity were compared. Further ahead regression correlation for a linear model was carried and the regression coefficients a and b were found out to be 0.2804 and 0.3618 respectively.
\end{abstract}

\section{INTRODUCTION}

The Sun's radiation enters the atmosphere of Earth and is considered one of the important sources of renewable form of energy for Earth's climate and all living life. Solar Energy, a renewable form of energy is a resource that primarily benefits countries in the tropical region. India being a tropical country, solar energy offers an abundant amount of power. This energy from the power is heat energy which is converted to electrical energy using a solar panel. A solar panel is a device that is installed in roofs or a field at an optimal tilted angle which uses photovoltaic cells to convert the heat energy to direct current electricity. The optimal tilt angle is generally equivalent to the latitude of the place where the panels are being installed. The value of this tilt angle also depends on the position and movement of the Sun.

The ever increase in demands for energy in-country and the need to reduce $\mathrm{CO}_{2}$ emissions play a crucial role to exploit the renewable form of energy. The radiations from the Sun are an important source of renewable energy. India has current solar capacity is about $37 \mathrm{GW}$ in the country [1]. India's Intended Nationally Determined Contributions (INDC) aims at an ambitious target of $40 \%$ of total power generation through renewable energy. This includes a target of also an installed capacity of $100 \mathrm{GW}$ of solar power by 2022 [2].

India holds a few of the largest solar parks in the world, Pavgada in Tumakuru, Bhadla Solar Park (Rajasthan), both of which have a capacity of over 2,000 MWp. Hence, it is important to ensure that there is an increase in the efficiency of yielding solar power. One way is to increase panel efficiency. NREL has designed an innovative solar cell that converts light energy into electricity at almost 50\% efficiency. This panel uses 140 layers of semiconductors to achieve that kind of efficiency [3].

This research studies how optimal tilt angle for the solar panels, increase the yield of each solar panel without the need of spending money on advanced and new solar panels. Our study in the paper has been focused only on the Solar radiation incident to Pune, India (latitude $18.5^{\circ}$ ). The study here was carried out to understand the relationship between global solar radiation and sunlight hours. Tilt angles of the mounted solar panels and various other factors such as the temperature and the moisture content in the atmosphere affect the total yield of the solar energy. A comprehensive study has been carried out in the following sections to study and discuss the effect and impact of the tilt angles of the solar panels, the effect of temperature having an impact on the solar panels, and finally, the presence of moisture (relative humidity) present in the atmosphere.

In the following sections, we have studied what other researchers have done in a similar field and found out that the model proposed by Liu and Jordan [4] was the most preferred model.

The objective of this research is in finding out the optimal tilt angle to increase the yield for each and every month, to establish the regression coefficients of the linear model, and 
finally to study the effect of temperature and relative humidity through graphical visualization.

The paper is organized in the following flow: Section (2) literature review, section (3) methodology, section 4 results and discussions and finally end with conclusions in section 5.

\section{LITERATURE REVIEW}

With the increase in the demand for energy in the industrial and domestic process, the need for producing more power has strained the sources of dispatchable energy to readily used resulting in the release of a huge amount of pollutants. Wind energy and Solar energy are tipped off as being the best alternate solution in meeting the surge in global energy supply in the coming decades. Researchers have been developing and testing different models for the ideal and almost real estimation of the total solar energy hitting the surface of the Earth. Some of the models are the linear regression model [5] and other non-linear models, as the quadratic model [6] and power model [7]. Manju and Sandeep [8] carried out a comparative analysis of linear, quadratic, cubic, quartic, logarithmic, exponential, power and inverse and ranked the models based on the site. Her research showed that the linear model performed extremely well in 6 of the 12 locations and quadratic, cubic performed well in other locations. Karakoti et al. [9] shows that all the models performed fairly well to estimate the mean monthly solar global irradiance for twentythree different stations in India. Recording the dust, cloud cover, aerosols and scattering of rays from the atmosphere [8] and also temperature and relative humidity [9] pose strong difficulties in estimation of solar radiation. The amount of solar radiation harnessed by any panel is depended on the absorption and orientation (tilt) of the panels. All the panels in the Northern hemisphere are oriented towards due south. The optimal tilt is purely based on the azimuth and the latitude of the place [10]. Several authors have shown that changing the orientation of the panel every month or on a seasonal basis has shown that much more energy can be yielded [11-16]. The best way is to optimize the tilt by active sun trackers and by changing the tilt angles of the panels. Malaysian researchers have recorded an increase in yield of about $5.03 \%$ if optimized monthly [17]. Researches at Dhaka have shown three methods for calculating [15]. Yadav and Chandel [18] calculated optimal tilt angles for 26 cities in India and found out that there was a $6.85 \%$ increase in comparison to the latitude of the place for Pune We have shown that there is an $8.18 \%$ increase in yield which is $1.3 \%$ more compared to the research done by Yadav and Chandel [18].

Optimizing the tilt every season in various cities in Maharashtra has shown an increase in yield by more than $6 \%$ in Nagpur, Thane, Kalyan-Dombivili, Aurangabad, Nanded, Shridi. [14] Jamil et al. [19] showed an improvement in yield by $12.92 \%$ (monthly optimized), $11.61 \%$ (optimized seasonally). The best angle of tilt for the solar panel is the latitude of the place. Jamil Ahmad and Tiwari [20] found that loss is only $1 \%$ using the Liu and Jordan model of approximation if the tilt is adjusted seasonally compared to adjusting monthly for New Delhi. Ihaddadene et al. [21] showed that different models yield slightly different results when it is compared to experimental data. Agarwal et al. [22] used different models for calculating the tilt for Chennai and Nagpur using different models. From the study of literature and researches are done on this field, Liu and Jordan $[4,23]$ is the most widely used model for optimization method.

To choose the right solar power configurations for a specific geographic location, it is helpful to understand the total radiative energy that is incident on the surface of the place. The understanding and knowledge of global solar radiation are important to predict the system's performance. One way of doing this is by associating the global solar irradiance with ground measurements of the place where data is collected [24].

\section{METHODOLOGY}

The data gathered for the study was secondary from NREL - NSDRB (National Renewable Energy Laboratory - National Solar Radiation Database) for the locations of Pune, from the years 2000-2014. NREL specialises in the sector of all renewable energy forms and research and development in energy efficiency. The Data points collected for this study were, GH (Global Horizontal Irradiance) in $\mathrm{W} / \mathrm{m}^{2}$, Temperature in ${ }^{\circ} \mathrm{C}$, Relative Humidity in percentage.

A liner model is given in Eq. (1) was used for calculation. The first time the relation between the global solar radiation and the sunlight hours was suggested by Angstrom. Prescott modified the equation given by Angstrom [5] which related average solar radiation and average sunshine hours.

$$
\frac{H}{H_{\mathrm{o}}}=a+b\left(\frac{n}{N_{\mathrm{o}}}\right)
$$

In the above Eq. (1) a \& b are the coefficients for the linear model for the place under study. $\frac{H}{H_{\mathrm{o}}}$ is the clearness index and $\frac{n}{N_{\mathrm{o}}}$ is the sunshine ratio. Many others formulated equations to obtain the relation between sunlight hours and solar global irradiance. The list is as follows.

\begin{tabular}{lcc}
\hline Model & Equation & Source \\
\hline Linear & $\frac{H}{H_{0}}=a+b\left(\frac{n}{N_{0}}\right)$ & [5] \\
\hline Quadratic & $\frac{H}{H_{0}}=a+\left(\frac{n}{N_{0}}\right) b+\left(\frac{n}{N_{0}}\right)^{2} c$ & [6] \\
\hline Power & $\frac{H}{H_{0}}=a *\left(\frac{n}{N_{0}}\right)^{b}$ & [7] \\
\hline
\end{tabular}

In this paper, the Linear model [5] is used in finding the values of the regression constants of $\mathrm{a} \& \mathrm{~b}$ for Pune, India. where,

$\mathrm{H}$ : average global solar radiation.

$\mathrm{H}_{\mathrm{o}}$ : average extra-terrestrial radiation.

The equation of $\mathrm{H}_{\mathrm{o}}$ is given as:

$$
\begin{gathered}
\mathrm{H}_{\mathrm{o}}=\frac{I_{s c}}{\pi}\left[1+0.033 * \cos \left(\frac{2 \pi N}{365}\right)\right]\left[\cos \varphi \cos \delta \sin \omega_{s}+\right. \\
\left.\frac{\pi}{180} \omega_{s} \sin \varphi \sin \delta\right]
\end{gathered}
$$

In the above Eq. (2) $\mathrm{I}_{\mathrm{sc}}$ is $1367 \mathrm{~W} / \mathrm{m}^{2}$ termed as the Solar Constant, $\mathrm{N}$ is the day number, $\varphi$ is $18.5^{\circ}$ in this study as it the latitude of the Pune. $\delta$ and $\omega_{s}$ are declination angle and mean sunshine hour angle given by the following equations:

$$
\begin{gathered}
\delta=23.45 * \sin \left(360 * \frac{[N+284]}{365}\right) \\
\omega_{s}=\cos ^{-1}(-\tan (\varphi) \tan (\delta))
\end{gathered}
$$


The amount of total solar radiation on any surface includes beam radiation, diffused radiation directly incident on the solar panel, and reflected radiation. When the Sun's rays enter the Earth's atmosphere roughly $16 \%$ of the radiation is diffused and is called diffused radiation, and some of the radiation also gets reflected by the Earth's surface and other reflective objects. This is called the reflected radiation. Hence the sum of diffused radiation reflected radiation and direct or beam radiation is called the global radiation. For maximum utilization of this radiation the solar panels are tilted at an angle $(\beta)$

Hence the equation for the global solar radiation is expressed as,

$$
\mathrm{G}_{\mathrm{t}}=\mathrm{B}_{\mathrm{t}}+\mathrm{D}_{\mathrm{t}}+\mathrm{R}_{\mathrm{t}}
$$

where, $G_{t}$ is defined as the Global Radiation on the tilted surface, $B_{t}$ is defined as the total Beam Radiation on the tilted surface, $D_{t}$ is defined as the total Diffused Radiation on the tilted surface and $\mathrm{R}_{\mathrm{t}}$ is defined as the total Reflected Radiation on the tilted surface.

Several models have been developed to calculate the global radiation for a tilted surface from the data collected on a horizontal surface. This paper uses the isotropic model suggested by Liu and Jordan [4] to calculate the optimal tilt angle of the solar panels. The isotropic model assumes that the diffused radiation is the same and uniform throughout the sky dome. This model is simply chosen for the ease of calculation it offers and it does increase the yield considerably.

Eq. (5) can also be expressed as:

$$
\mathrm{G}_{\mathrm{t}}=\left(\mathrm{G}_{\mathrm{H}}-\mathrm{D}_{\mathrm{H}}\right) \mathrm{R}_{\mathrm{B}}+\mathrm{DR} \mathrm{R}_{\mathrm{D}}+\mathrm{G} \rho \mathrm{R}_{\mathrm{R}}
$$

where, $\rho$ is reflectivity constant or also known as the Earth's albedo of the ground which is anywhere between $0.1-0.4$ for land, but for ease of calculation, in this present work the value for $\rho$ (reflectivity constant) is taken as 0.3 as it is the average albedo throughout the Earth, and $\mathrm{G}_{\mathrm{H}}$ is known as the measured overall global irradiance on the horizontal surface and $\mathrm{D}_{\mathrm{H}}$ can either be derived through empirical formulas given in Eq. (7) and Eq. (8) or be measured in the place is known as the Diffused solar radiation. In this study, the value for $\mathrm{D}_{\mathrm{H}}$ (Diffused Irradiance on the horizontal surface) is derived from the global solar irradiance. The model here is compared with both theoretical calculation given by the equation:

$$
\mathrm{D}_{\mathrm{H}}=0.165^{*} \mathrm{G}_{\mathrm{H}}\left(\text { for } \mathrm{K}_{\mathrm{t}} \geq 0.8\right)
$$

$$
\begin{gathered}
\mathrm{D}_{\mathrm{H}}=\mathrm{G}_{\mathrm{H}}\left(0.95-0.16\left(\mathrm{~K}_{\mathrm{t}}\right)+4.3\left(\mathrm{~K}_{\mathrm{t}}\right)^{2}-16.4\left(\mathrm{~K}_{\mathrm{t}}\right)^{3}+12.3\left(\mathrm{~K}_{\mathrm{t}}\right)^{4}\right) \\
\left(\text { for } 0.22 \leq \mathrm{K}_{\mathrm{t}} \leq 0.8\right)
\end{gathered}
$$

where, $\mathrm{K}_{t}$ is called the clearance index $\left(\mathrm{H} / \mathrm{H}_{\mathrm{o}}\right)$, defined as the measure of clearance in the atmosphere. Typically the value of this is between 0 and 1 and usually ranges from 0.25 to 0.9 .

From Eq. (3), $R_{B}$ is defined as the ratio between monthly mean beam radiation on the angled (tilt) surface and the surface which is horizontal, $\mathrm{R}_{\mathrm{D}}$ is defined as the ratio between mean monthly diffuse radiation absorbed in a unit area of the angled (tilt) surface and unit area of the horizontal surface, and $R_{R}$ is defined as the total solar energy reflected on that surface.

$$
\mathrm{R}_{\mathrm{B}}=\frac{\sin (\omega) \cos (\delta) \cos (\varphi-\beta)+\omega \sin (\delta) \sin (\varphi-\beta)}{\sin (\omega) \cos (\delta) \cos (\varphi)+\omega \sin (\delta) \sin (\varphi)}
$$

$$
\begin{aligned}
& \mathrm{R}_{\mathrm{D}}=\frac{1+\cos (\beta)}{2} \\
& \mathrm{R}_{\mathrm{R}}=\frac{1-\cos (\beta)}{2}
\end{aligned}
$$

where,

$\omega$ : Sunshine hour angle.

$\delta$ : declination angle.

$\beta$ : Angle of tilt.

In the above equation $\mathrm{n}$ is the day number and it is taken as 1 for January $1^{\text {st }}$ and 365 for December $31^{\text {st }}$.

For this research paper, the average monthly solar radiation is measured by taking the respective' month mid-day for ease of calculation which is the $15^{\text {th }}$ of every month. And $\omega$ is given by,

$\varphi$ is $18.5^{\circ}$ (latitude of Pune) which is considered for calculation

The tilt angle $\beta$ is varied from $0^{\circ}$ to $90^{\circ}$ in this current work. Combining the Eqns. (6), (7) and (8) Eq. (3), the total radiation on a tilted surface can be written as:

$$
\begin{aligned}
\mathrm{G}_{\mathrm{t}}=\left(\mathrm{G}_{\mathrm{H}}-\mathrm{D}_{\mathrm{H}}\right) & \frac{\sin (\omega) \cos (\delta) \cos (\varphi-\beta)+\omega \sin (\delta) \sin (\varphi-\beta)}{\sin (\omega) \cos (\delta) \cos (\varphi)+\omega \sin (\delta) \sin (\varphi)} \\
& +\mathrm{D}_{\mathrm{H}} \frac{1+\cos (\beta)}{2}+\mathrm{G} \rho \frac{1-\cos (\beta)}{2}
\end{aligned}
$$

Using the Eqns. (1) to (5), the regression coefficients a \& b were calculated in MS-EXCEL. Eqns. (6) to (12) were used to calculate the optimal tilt angles from using MS-EXCEL. The angle at which there is maximum yield is called the optimal tilt angle of that month.

\section{RESULTS AND DISCUSSIONS}

The years considered for analysis are from $2009-2014$. The monthly optimal tilt angles are calculated using MS-EXCEL. For calculating the optimal tilt angle, $\beta$ is changed from $0^{\circ}$ to $90^{\circ}$ at an interval of $1^{\circ}$. The angle at which there is maximum yield is coined as the optimal tilt angle of that month. It was found that the optimal tilt angle for Pune was found to be $50^{\circ}$, $40^{\circ}, 24^{\circ}, 4^{\circ}$ for January, February, March, April respectively, $0^{\circ}$ for the months' May to August and 17, 35, 48, 52 for the months September, October, November, December respectively. These values are different from the latitude of the place of Pune which is $18.5^{\circ}$, which was originally considered are the tilt angle for the solar panels.

This paper also established the relationship between the yield of solar energy to the atmospheric humidity and atmospheric temperature for Pune

The obtained results of mean monthly averages of solar radiation and its relation with temperature in ${ }^{\circ} \mathrm{C}$ and relative humidity are discussed in the next section. The regression coefficients and obtained tilt angles for the solar angles and also tabulated and the effects and implications of estimating the solar radiation and the increase in yield of absorbed solar energy are both tabulated and discussed respectively. The empirical correlation is shown in Eq. (1) along with the equations from (2) to (4) are used to establish the values for the coefficients a \& b of the linear model.

\subsection{Optimal tilt angle}

Pune lies in the northern hemisphere, which means that, the orientation for the solar panel will be due south at the angle of 
$18.5^{\circ}$, which is the latitude of Pune, for fixed solar panels. The results from Eq. (12), that the value of $\mathrm{G}_{\mathrm{t}}$ is shown in Table 1 . In the present work, the value of $\beta$ is varied from $0^{\circ}$ to $90^{\circ}$ for every month and the angle at which the solar radiation is highest is coined as the optimal tilt for that month. The optimal angles are tabulated in Table 2. This table shows that in the summer months (May to August) the tilt is of the panel is $0^{\circ}$. This is because the sun is directly overhead as the sun path traces the northern sky. The rest of the months' tilt angles are $17^{\circ}$ (September), $35^{\circ}$ (October), $48^{\circ}$ (November), $52^{\circ}$ (December), $50^{\circ}$ (February) and $24^{\circ}$ (March). This is because the Sun traces the southern part of the sky majorly in the months from October to February, thus seeing such high values of tilt angles.
Table 1. Calculated Values for $\mathrm{G}_{\mathrm{t}}$ (2014)

\begin{tabular}{c|ccccccccc}
\hline \multirow{2}{*}{ Tilt $^{0}$} & \multicolumn{10}{|c}{$\mathrm{G}_{\mathrm{t}}$} \\
\cline { 2 - 9 } & Jan & Feb & Mar & Apr &. & Sep & Oct & Nov & Dec \\
\hline 0 & 446 & 521 & 523 & 541 &. & 451 & 483 & 453 & 430 \\
. &. &. &. &. &. &. &. &. &. \\
. &. &. &. &. &. &. &. &. &. \\
18.5 & 558 & 608 & 559 & 528 &. & 466 & 547 & 557 & 549 \\
19 & 560 & 610 & 559 & 527 &. & 466 & 548 & 559 & 552 \\
. &. &. &. &. &. &. &. &. &. \\
. &. &. &. &. &. &. &. &. &. \\
88 & 522 & 475 & 314 & 166 &. & 220 & 389 & 500 & 540 \\
89 & 516 & 468 & 307 & 159 &. & 214 & 383 & 494 & 535 \\
90 & 510 & 461 & 300 & 152 &. & 208 & 376 & 488 & 529 \\
\hline
\end{tabular}

Table 2. Optimal tilt angles

\begin{tabular}{cccccccccc}
\hline & Jan & Feb & Mar & Apr & May-Aug & Sep & Oct & Nov & Dec \\
\hline 2009 & $50^{\circ}$ & $40^{\circ}$ & $24^{\circ}$ & $4^{\circ}$ & $0^{\circ}$ & $17^{\circ}$ & $35^{\circ}$ & $48^{\circ}$ & $52^{\circ}$ \\
2010 & $50^{\circ}$ & $40^{\circ}$ & $24^{\circ}$ & $4^{\circ}$ & $0^{\circ}$ & $17^{\circ}$ & $35^{\circ}$ & $48^{\circ}$ & $52^{\circ}$ \\
2011 & $50^{\circ}$ & $40^{\circ}$ & $24^{\circ}$ & $4^{\circ}$ & $0^{\circ}$ & $17^{\circ}$ & $35^{\circ}$ & $48^{\circ}$ & $52^{\circ}$ \\
2012 & $50^{\circ}$ & $40^{\circ}$ & $24^{\circ}$ & $3^{\circ}$ & $0^{\circ}$ & $17^{\circ}$ & $36^{\circ}$ & $48^{\circ}$ & $52^{\circ}$ \\
2013 & $50^{\circ}$ & $40^{\circ}$ & $24^{\circ}$ & $4^{\circ}$ & $0^{\circ}$ & $17^{\circ}$ & $35^{\circ}$ & $48^{\circ}$ & $52^{\circ}$ \\
2014 & $50^{\circ}$ & $40^{\circ}$ & $24^{\circ}$ & $4^{\circ}$ & $0^{\circ}$ & $17^{\circ}$ & $35^{\circ}$ & $48^{\circ}$ & $52^{\circ}$ \\
\hline
\end{tabular}

Table 3. \% Increase in yield

\begin{tabular}{ccccccc}
\hline Year & $\mathbf{2 0 0 9}$ & $\mathbf{2 0 1 0}$ & $\mathbf{2 0 1 1}$ & $\mathbf{2 0 1 2}$ & $\mathbf{2 0 1 3}$ & $\mathbf{2 0 1 4}$ \\
\hline $\begin{array}{c}\% \\
\text { increase } \\
\text { (monthly) } \\
\%\end{array}$ & $8.18 \%$ & $8.18 \%$ & $8.18 \%$ & $8.22 \%$ & $8.18 \%$ & $8.18 \%$ \\
$\begin{array}{c}\text { increase } \\
(2 \text { times) }\end{array}$ & $6.55 \%$ & $7.27 \%$ & $7.24 \%$ & $7.26 \%$ & $7.27 \%$ & $7.24 \%$ \\
\hline
\end{tabular}

Table 3 shows the increase in yield if the tilts of the solar panels are optimized. The values in Table 3 are concerning the yield in solar energy if the panels were inclined at an angle of $18.5^{\circ}$.

The graphical representation of yields is shown in Figure 1. The graph compares the solar radiation yielded when it is fixed at $18.5^{\circ}$ throughout the year, optimized twice in a year i.e in April \& October, and optimized every month.

If the tilt of the panels is optimized every month the increase in yield is more than $8 \%$. If the angle of tilt is optimized twice a year, i.e. once in April $\left(\beta=0^{\circ}\right)$ and the second time in October $\left(\beta=40^{\circ}\right)$ the increase in yield is more than $7 \%$. The angle of tilt is taken as $40^{\circ}$ since the angles from October to March lies between $35^{\circ}$ to $52^{\circ}$. The results for this are shown in Table 4.

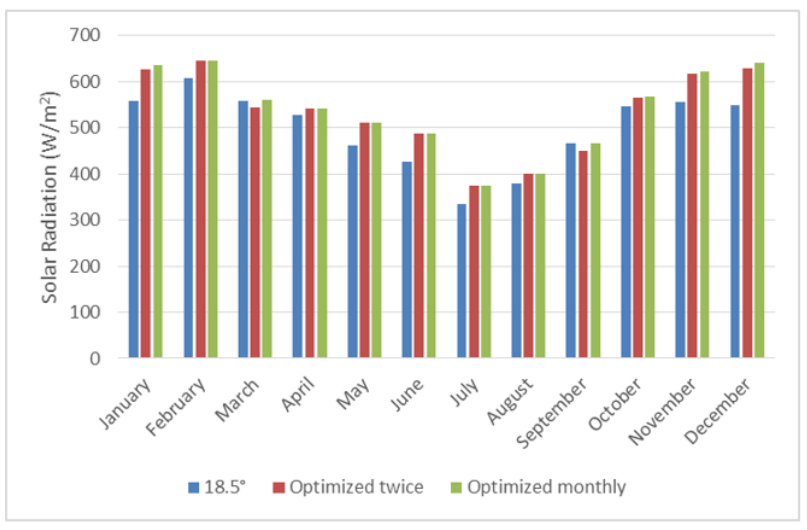

Figure 1. Comparison of yield between three scenarios

\subsection{Global solar radiation}

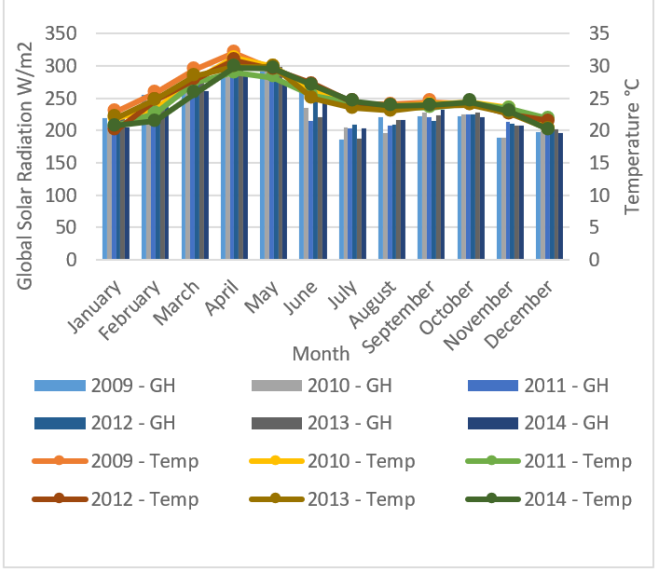

Figure 2. Comparison of monthly averages between solar radiation and temperature

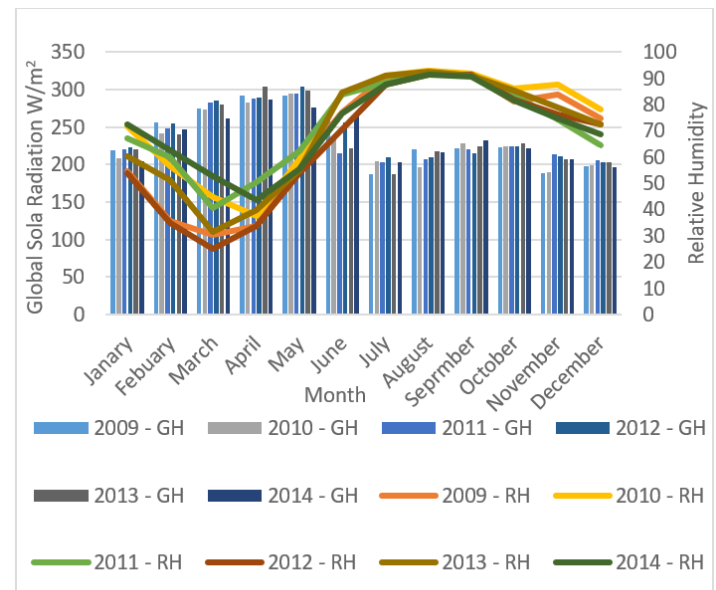

Figure 3. Comparison of monthly averages between solar radiation and relative temperature 
Figure 2 shows the comparison between the average monthly solar radiation and average temperature. From the graph, it is evident that as the onset of summer approaches the average yields are maximum during the month's March, April, and May. This trend also shows the effect of the monsoon in the months starting from June and lasting till August, and sometimes even September. Factors such as cloud cover, wind speed, relative humidity, and clearness index affect the solar radiation incident on the solar panel. Observing Figure 3, it is conclusive that, as the relative humidity rises the solar yield decreases. The significance of Figure 2 shows the effect of temperature and Figure 3 depicts the effect of how relative humidity has a major impact on the amount of solar energy yielded in a single place.

\subsection{Regression analysis}

The Linear model was used for the years 2009, 2011, 2012, 2013, and 2014 and the corresponding regression values are shown in Table 4.

Table 4. Regression Coefficients observed for different years

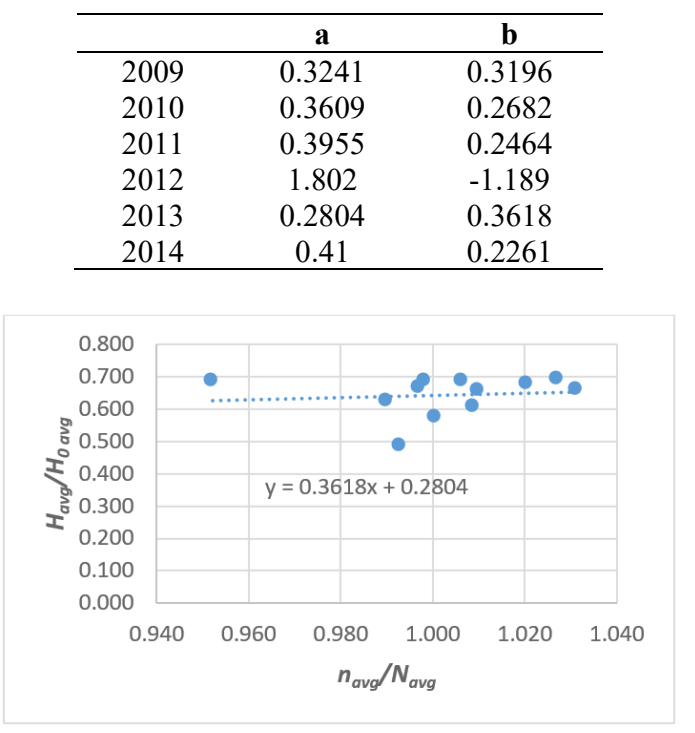

Figure 4. Scatter Plot (2013)

The calculated values were measured values as mentioned in Eq. (1). Through a scatter plot the findings of the regression coefficients are illustrated (Figure 4). The values for which are mentioned in Table 4. To verify the validity of the model and the correctness and of the correlation coefficients the values were compared to measured data found out by GD Rai.

The actual values of regression coefficients as tabulated by G.D Rai is $a=0.31, b=0.43$ and as pointed out by Manju and Sandeep [8] $\mathrm{a}=0.4505, \mathrm{~b}=0.2706$.

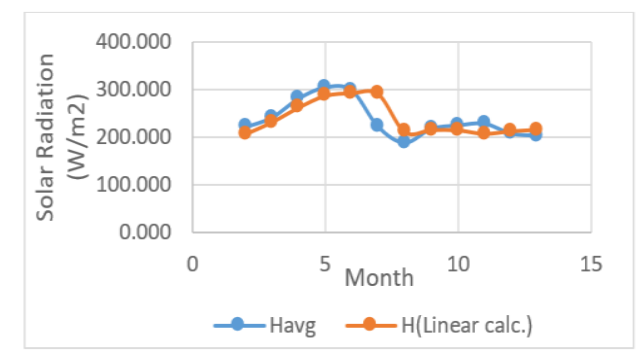

Figure 5. Measured monthly average global $\left(\mathrm{W} / \mathrm{m}^{2}\right)$ with the calculated value of global solar radiation $\left(\mathrm{W} / \mathrm{m}^{2}\right)$
Comparison between the measured value and calculated value using the correlation coefficients. The values of measured monthly averages of global solar radiation, sunshine hours and are compared to the calculated value using correlation coefficients obtained from the linear model. Figure 5 depicts the comparison between the measured monthly average global $\left(\mathrm{W} / \mathrm{m}^{2}\right)$ with the calculated value of global solar radiation $\left(\mathrm{W} / \mathrm{m}^{2}\right)$ from the liner model for Pune.

\section{CONCLUSION}

The above study establishes the reliability of the linear model for the area of Pune. From the measured data, it was observed that the average radiation was increasing in March, April, and May. Based on the current study is evidence that the effect of relative humidity had an impact on the final yield of solar energy. It's safe to say that other factors such as cloud, rain, dust, aerosols might also have affected the final yield. The value of regression coefficients, i.e. $a$ and $b$ is 0.2804 and 0.3618 respectively which is very close to the value pointed out by GD Rai as the value of $a$ is 0.31 and that of $b$ is 0.43 . The regression coefficients of 2012 are way off from the standard value and also the value of $\mathrm{a}$ and $\mathrm{b}$ from the years 2009, 2010, 2011, 2013, and 2014.

The tilt angle optimized for the solar panels play a crucial part in enhancing the total amount of solar energy collected in the panel. To maximize the yield the panels should be mounted facing the Southern sky and optimize the tilt angle every month. By optimizing the tilt every month, the increase in yield is more than $8 \%$ compared to fixing the panel at an angle of $18^{\circ}$ due South. There is also an increase in the yield by $7 \%$ if the tilt was changed twice, once in April where it's best to keep the solar flat and once again in October at an angle of $40^{\circ}$.

It is also shown that how temperature and relative humidity influence the yield of solar energy. However, the extent to which these factors influence is not studied and are only observed through graphs. Various other factors such as $\mathrm{CO}_{2}$ concentration, wind speed, dust, and aerosols present in the atmosphere are difficult in capturing and recording. These can also result in estimation errors. In this paper the since the data gathered was through NREL-NSRDB, the power output of the solar photovoltaic cells is unknown. An experimental setup which consists of two panels, one PV system reads the radiation at an inclination of $18.5^{\circ}$ and another panel could be optimally tilted every month for a year and the results could be tabulated and checked with the results tabulated in this paper. This is the scope of future work. Alternatively, a solar tracking system could also be used to increase the efficiency of the solar panels.

\section{REFERENCES}

[1] Government of India (2020). Ministry of New and Renewable https://mnre.gov.in/\#search_notification.

[2] Government of India (Government) (2020). India plans to produce $175 \mathrm{GW}$ of renewable energy by 2022 . United Nations Partnerships for SDGs platform. https://sustainabledevelopment.un.org/partnership/?p=3 4566

[3] Mazengarb, M. (2020). Scientists set new solar power efficiency record at almost 50 per cent. RenewEconomy. 
https://reneweconomy.com.au/scientists-set-new-solarpower-efficiency-record-at-almost-50-per-cent-71555/

[4] Liu, B., Jordan, R. (1962). Daily insolation on surfaces tilted towards the equator. Trans. ASHRAE, 67: 526-541.

[5] Angstrom, A. (1924). Solar and terrestrial radiation. 19. Monthly WeatherReview, 52(8): 397-397.

[6] Ögelman, H., Ecevit, A., Tasdemiroğlu, E. (1984). A new method for estimating solar radiation from bright sunshine data. Solar Energy, 33(6): 619-625. https://doi.org/10.1016/0038-092X(84)90018-5

[7] Toğrul, I.T., Toğrul, H. (2002). Global solar radiation over Turkey: Comparison of predicted and measured data. Renewable Energy, 25(1): 55-67. https://doi.org/10.1016/S0960-1481(00)00197-X

[8] Manju, S., Sandeep, M. (2019). Prediction and performance assessment of global solar radiation in Indian cities: A comparison of satellite and surface measured data. Journal of Cleaner Production, 230: 116128. https://doi.org/10.1016/j.jclepro.2019.05.108

[9] Karakoti, I., Das, P.K., Singh, S.K. (2012). Predicting monthly mean daily diffuse radiation for India. Applied Energy, 91(1): 412-425. https://doi.org/10.1016/j.apenergy.2011.10.012

[10] Bari, S. (2001). Optimum orientation of domestic solar water heaters for the low latitude countries. Energy Conversion and Management, 42(10): 1205-1214. https://doi.org/10.1016/S0196-8904(00)00135-7

[11] Markam, K., Sudhakar, K. (2016). Estimation of optimal tilt angle for solar photovoltaic installations in India. International Research Journal of Engineering and Technology, 3(5): 2735-2741.

[12] Kumar, A., Thakur, N.S., Makade, R., Shivhare, M.K. (2011). Optimization of tilt angle for photovoltaic array. International Journal of Engineering Science and Technology, 3(4): 3153-3161.

[13] Safdarian, F., Nazari, M.E. (2015). Optimal tilt angle and orientation for solar collectors in Iran. In 2015 IEEE 10th International Symposium on Diagnostics for Electrical Machines, Power Electronics and Drives (SDEMPED), pp. 494-500. https://doi.org/10.1109/DEMPED.2015.7303735

[14] Lanjewar, A.B., Tete, I.P., Joshi, S.S. (2016). Determination of optimum tilt angle of solar collectors for solar cities in Maharashtra, India. Emerg. Trends Sci. Technol. Manag., 1: 94-97.

[15] Ghosh, H.R., Bhowmik, N.C., Hussain, M. (2010). Determining seasonal optimum tilt angles, solar radiations on variously oriented, single and double axis tracking surfaces at Dhaka. Renewable Energy, 35(6): 1292-1297. https://doi.org/10.1016/j.renene.2009.11.041

[16] Uba, F.A., Sarsah, E.A. (2013). Optimization of tilt angle for solar collectors in WA, Ghana. Pelagia Research Library, Advances in Applied Science Research, 4(4): 108-114.

[17] Khatib, T., Mohamed, A., Mahmoud, M., Sopian, K. (2015). Optimization of the tilt angle of solar panels for Malaysia. Energy Sources, part A: Recovery, Utilization, and Environmental Effects, 37(6): 606-613. https://doi.org/10.1080/15567036.2011.588680

[18] Yadav, A.K., Chandel, S.S. (2018). Formulation of new correlations in terms of extraterrestrial radiation by optimization of tilt angle for installation of solar photovoltaic systems for maximum power generation: case study of 26 cities in India. Sādhanā, 43(6): 1-15. https://doi.org/10.1007/s12046-018-0858-2

[19] Jamil, B., Siddiqui, A.T., Akhtar, N. (2016). Estimation of solar radiation and optimum tilt angles for southfacing surfaces in Humid Subtropical Climatic Region of India. Engineering Science and Technology, an International Journal, 19(4): 1826-1835. https://doi.org/10.1016/j.jestch.2016.10.004

[20] Jamil Ahmad, M., N Tiwari, G. (2009). Optimization of tilt angle for solar collector to receive maximum radiation. The Open Renewable Energy Journal, 2(1): 19-24. https://doi.org/10.2174/1876387100902010019

[21] Ihaddadene, N., Ihaddadene, R., Charik, A. (2017). Best tilt angle of fixed solar conversion systems at M'Sila Region (Algeria). Energy Procedia, 118: 63-71. https://doi.org/10.1016/j.egypro.2017.07.014

[22] Agarwal, A., Vashishtha, V.K., Mishra, S.N. (2012). Solar tilt measurement of array for building application and error analysis. International Journal of Renewable Energy Research (IJRER), 2(4): 781-789.

[23] Liu, B.Y., Jordan, R.C. (1960). The interrelationship and characteristic distribution of direct, diffuse and total solar radiation. Solar Energy, 4(3): 1-19. https://doi.org/10.1016/0038-092X(60)90062-1

[24] Sekar, M., Sakthivel, M., Kumar, S.S., Ramesh, C. (2012). Estimation of global solar radiation for Chennai. European Journal of Scientific Research, 73(3): 415-424.

\section{NOMENCLATURE}

$\mathrm{D}_{\mathrm{H}} \quad$ Direct Radiation (Horizontal) $\left(\mathrm{W} / \mathrm{m}^{2}\right)$

$\mathrm{G}_{\mathrm{H}} \quad$ Global Radiation (Horizontal) $\left(\mathrm{W} / \mathrm{m}^{2}\right)$

$\mathrm{G}_{\mathrm{t}} \quad$ Global Radiation on tilted Surface $\left(\mathrm{W} / \mathrm{m}^{2}\right)$

$\mathrm{B}_{\mathrm{t}} \quad$ Beam Radiation on tilted Surface $\left(\mathrm{W} / \mathrm{m}^{2}\right)$

D Diffused Radiation on tilted Surface $\left(\mathrm{W} / \mathrm{m}^{2}\right)$

R Reflected Radiation on tilted Surface $\left(\mathrm{W} / \mathrm{m}^{2}\right)$

$\mathrm{H} \quad$ Average Solar radiation $\left(\mathrm{W} / \mathrm{m}^{2}\right)$

$\mathrm{H}_{\mathrm{o}} \quad$ Average extra-terrestrial radiation $\left(\mathrm{W} / \mathrm{m}^{2}\right)$

$\mathrm{K}_{\mathrm{t}} \quad$ Clearness Index $\left(\mathrm{H} / \mathrm{H}_{\mathrm{o}}\right)$

$\mathrm{N}$ Day number of the year

n Sunlight Hours (hrs)

$\mathrm{N}_{0} \quad$ Maximum Sunlight hours Possible (hrs)

RH Relative Humidity

\section{Greek symbols}

$\rho \quad$ Reflectivity index for ground

$\varphi \quad$ Latitude of Pune which is $18.5^{\circ}$

$\beta \quad$ Angle of tilt $\left(^{\circ}\right)$

$\delta \quad$ Angle of declination $\left({ }^{\circ}\right)$

$\omega \quad$ Sunshine hour angle $\left(^{\circ}\right)$ 